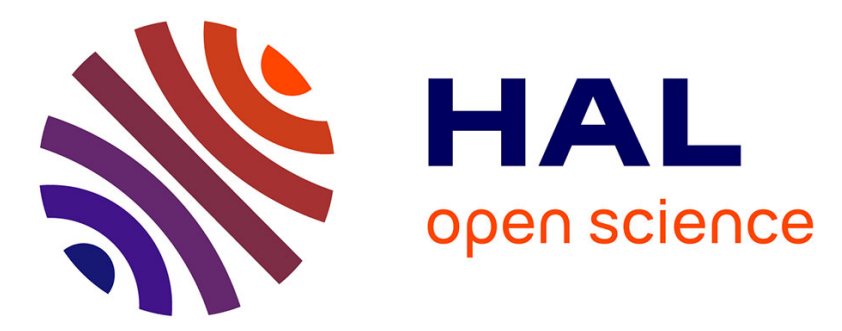

\title{
Synthesis of double hydrophilic block copolymers and induced assembly with oligochitosan for the preparation of polyion complex micelles
}

Julien Reboul, T. Nugay, N. Anik, H. Cottet, V. Ponsinet, Martin In, Patrick Lacroix-Desmazes, Corine Gerardin

\section{To cite this version:}

Julien Reboul, T. Nugay, N. Anik, H. Cottet, V. Ponsinet, et al.. Synthesis of double hydrophilic block copolymers and induced assembly with oligochitosan for the preparation of polyion complex micelles. Soft Matter, 2011, 7 (12), pp.5836-5846. 10.1039/c1sm05230f . hal-00602565

\section{HAL Id: hal-00602565 https://hal.science/hal-00602565}

Submitted on 29 Jul 2021

HAL is a multi-disciplinary open access archive for the deposit and dissemination of scientific research documents, whether they are published or not. The documents may come from teaching and research institutions in France or abroad, or from public or private research centers.
L'archive ouverte pluridisciplinaire HAL, est destinée au dépôt et à la diffusion de documents scientifiques de niveau recherche, publiés ou non, émanant des établissements d'enseignement et de recherche français ou étrangers, des laboratoires publics ou privés. 


\title{
Synthesis of double hydrophilic block copolymers and induced assembly with oligochitosan for the preparation of polyion complex micelles
}

\author{
J. Reboul, ${ }^{a}$ T. Nugay, ${ }^{a}$ N. Anik, ${ }^{b}$ H. Cottet, ${ }^{b}$ V. Ponsinet, ${ }^{c}$ M. In, ${ }^{d}$ P. Lacroix-Desmazes ${ }^{* a}$ and C. G ${ }^{\prime}$ erardin ${ }^{* a}$
}

This paper reports on the polyion complex micelles (PIC micelles) formed between neutral-ionizable double hydrophilic block copolymers (DHBC), poly(ethylene oxide)-block-poly(acrylic acid) (PEO-b-PAA), and oligochitosan, a natural polyamine. The controlled synthesis of PEO- $b$-PAA polymers was achieved by atom transfer radical polymerization (ATRP) of tert-butyl acrylate with $\omega$-bromide-functionalized PEO macroinitiators $\left(M_{\mathrm{w}}=2000\right.$ and $\left.5000 \mathrm{~g} \mathrm{~mol}^{-1}\right)$ and the subsequent deprotection reaction under acidic conditions. A series of copolymers with a narrow molecular weight distribution $\left(M_{\mathrm{w}} / M_{\mathrm{n}} \leq 1.2\right)$ and varied PAA block lengths was synthesized. Capillary electrophoresis (CE) was shown to unambiguously prove the blocky structure of the copolymers. It also showed that about $60 \%$ of the sodium counter ions were condensed onto the polyacrylate block in the pure diblock copolymer solution, which is consistent with the formation of polyion complex micelles triggered by counter-ion release in the presence of oligochitosan. The formation of oligochitosan/PAA-PEO core-corona micelles has been investigated by dynamic light scattering (DLS), small angle X-ray scattering (SAXS) and transmission electron microscopy (TEM). A minimum length of the PAA block is necessary to ensure micelle formation. The range of $\mathrm{pH}$, where PIC micelles form, critically depends on the PAA block length, which also determines the size of the micelles. Micelles can be dissociated at ionic strength above 0.4 mol L ${ }^{-1}$. Since these PIC micelles have been used as recyclable structuring agents for the formation of ordered mesoporous materials, the reversibilty of the assembling process was studied upon $\mathrm{pH}$ and ionic strength cyclic variations. A hysteresis of stability was observed at low pH, probably due to hydrogen bonding.

\section{Introduction}

Recently, double hydrophilic block copolymers (DHBC) have attracted much interest because of their potential in various applications, such as crystal growth modification, ${ }^{1,2}$ metal oxide particle stabilization, ${ }^{3-5}$ responsive polymer materials for sensing, optics, ${ }^{6}$ diagnostics and controlled drug delivery. ${ }^{\mathbf{7} 8}$ These copolymers are entirely soluble in water, but under appropriate conditions of $\mathrm{pH}$, ionic strength, temperature,

\footnotetext{
anstitut Charles Gerhardt-UMR 5253 CNRS/UM2/ENSCM/UM1, Ecole Nationale Superieure de Chimie de Montpellier, 8 rue de l'Ecole Normale, 34296 Montpellier Cedex 5, France.

E-mail: patrick. lacroix-desmazes@enscm.fr; corine.gerardin@enscm.fr; Fax: (+33) 467147220

bInstitut des Biomolecules Max Mousseron-UMR 5247 CNRS/UM1/ UM2, Universite Montpellier 2, Place Eugene Bataillon, 34095 Montpellier Cedex 5, France

'Unuversite Bordeaux1-CNRS, Centre de Recherche Paul Pascal UPR8641, 115 avenue Schweitzer, 33600 Pessac, France

${ }^{\mathrm{d}}$ Laboratoire Charles Coulomb - UMR 5221, Universite Montpellier 2, 34095 Montpellier cedex 5, France
}

addition of an oppositely charged polyelectrolyte, one of the two polymer blocks can become insoluble in water leading to micellisation. ${ }^{9}$ Among DHBC-based assemblies, micelles resulting from electrostatic interactions between the polyionic block of a neutral-ionic DHBC and ionic species of opposite charge are of particular interest. Micellisation results from the controlled and inhibited growth of the insoluble complex phase due to the presence of the solvated neutral polymer blocks of the DHBC. Stable polyelectrolyte complexes (PEC), interpolyelectrolyte complexes (IPEC) ${ }^{10-12}$ or polyplexes ${ }^{13}$ in aqueous solution can be prepared by using one or two neutral-polyelectrolyte DHBC. It has been shown that the structural characteristics and stability of such polyion complex (PIC) micelles formed by an electrostatically driven assembly of polyelectrolytes are dependent on parameters such as the $\mathrm{pH}$ and ionic strength of the medium, the mixing composition and length of the different polymer chains. ${ }^{14-21}$

As the assembling process of DHBC can be triggered by variations of physico-chemical conditions of the aqueous medium, DHBC micelles are good candidates for controlled drug release systems or reversible structure directing agents (SDA) for the synthesis of ordered mesoporous materials (OMMs). In 
a previous paper, we reported that polyion complex micelles could be used as new SDA of ordered mesoporous silica. ${ }^{22}$ OMMs are characterized by large specific surface areas, ordered pore systems and well defined pore size distributions centered on values most often comprised between 2 and $15 \mathrm{~nm} \cdot{ }^{23-26}$ They are traditionally prepared using assemblies of ionic or nonionic surfactants as templates. Neutral block copolymers constituted of a hydrophilic poly(ethylene oxide) (PEO) block able to interact with silica precursors and a water insoluble block responsible for the association via hydrophobic interactions have been commonly used. ${ }^{27,28}$ Despite the considerable knowledge acquired on mesoporous materials, the main limitation for their development at the industrial scale is the high cost, which is related to the SDA elimination step necessary to generate the porosity. Calcination of the amphiphilic SDA, which is until now the most efficient method, requires a high energy input and leads to the loss of the SDA. Washing in organic solvents, often performed in hot acidic solutions, is an interesting alternative route but it is still expensive and not environmentally friendly. ${ }^{26} \mathrm{We}$ proposed the use of induced and reversible DHBC micelles as new SDA removable and recyclable under environment-friendly conditions (in water, at room temperature and in $\mathrm{pH}$ conditions close to neutrality). The micelles were electrostatic complexes between a poly(ethylene oxide)- $b$-polyacid DHBC and a weak polybase: ${ }^{22}$ the particular case of PIC micelles of poly(ethylene oxide)- $b$-poly((meth)acrylic acid) (PEO- $b$-PMAA or PEO- $b$ PAA) and an oligochitosan is examined here in detail. Complexation with other synthetic polyamines, such as polyethyleneimine or polyvinylpyridine, was also studied and also leads to $\mathrm{pH}$-sensitive reversible well-defined PIC micelles, but only the particular case of oligochitosan is presented here, since it presents advantages due to its natural origin and its biocompatibility. Micelles were formed in a precise intermediate $\mathrm{pH}$ range, as proposed in Fig. 1 . In that $\mathrm{pH}$ range (around $\mathrm{pH} \approx$ $5.5)$, the presence of an inorganic silica precursor leads to the elaboration of ordered mesostructured hybrid silica based materials. The SDA was then extracted by washing the material in water at $\mathrm{pH} 7.7$, where micelles dissociate (outside the micelle formation $\mathrm{pH}$ domain); DHBCs and oligochitosan were thus recovered and recycled for other synthesis runs.

To the best of our knowledge, the formation and dissociation processes of PEO- $b$-PAA/oligochitosan complex micelles have never been studied yet. The scope of this paper is to give a deeper description of the $\mathrm{pH}$-induced reversible assemblies used as new

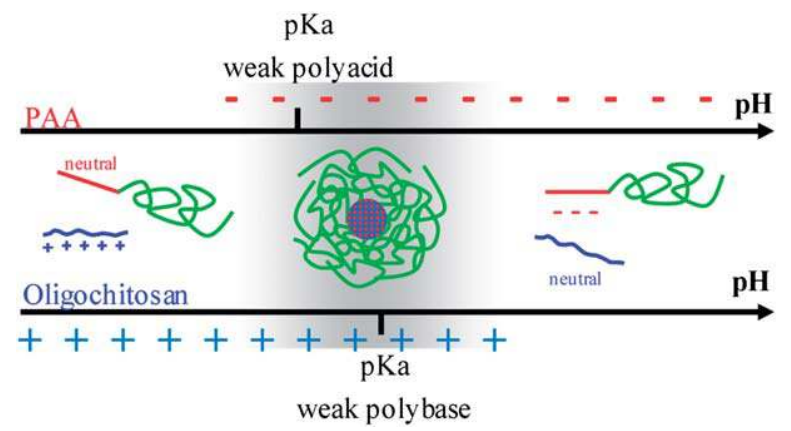

Fig. 1 Schematic presentation of the behaviour of the PEO-b-PAA/ oligochitosan system as a function of $\mathrm{pH}$. structuring agents of inorganic materials. With this aim, PEO- $b$ PAA DHBCs with variable PAA block lengths were synthesized by atom transfer radical polymerization (ATRP). The DHBC effective charge was determined by capillary electrophoresis (CE) using indirect UV detection. ${ }^{29}$ This method allowed confirmation of the diblock architecture of the copolymer and determining the fraction of counter-ions condensed on the polyelectrolyte block.

The $\mathrm{pH}$ range of complex micelle formation was then investigated by dynamic light scattering (DLS). The aggregates were characterized by transmission electron microscopy (TEM) and small angle X-ray scattering (SAXS). Reversibility of the micellization process, upon variation of either $\mathrm{pH}$ or ionic strength, was studied by DLS, too.

Finally, in order to study the effect of the DHBC symmetry degree on formation of micellar assemblies, mixtures of oligochitosan and copolymers with variable PAA block lengths were investigated. It is well known that the hydrophilic/hydrophobic volume ratio of amphiphilic block copolymers typically used as templates has a direct effect on the curvature of the obtained mesostructures. ${ }^{26,30}$ The present study on micelle formation in the absence of any inorganic precursor allowed us to determine the $\mathrm{pH}$ conditions for micelle formation and dissociation as a function of the PAA length for a given PEO block length.

\section{Experimental}

\section{(a) Materials}

tert-Butyl acrylate (tBuA, Aldrich, 98\%) was stirred on $\mathrm{CaH}_{2}$ for two hours and was purified by vacuum distillation. Toluene (Aldrich, 99.5\%) and THF (Aldrich, 99.9\%) were distilled over sodium benzophenone (Avocado, 99\%). CuBr (Aldrich, 98\%) was purified by stirring with glacial acetic acid. After filtration, it was washed with absolute ethanol and diethyl ether and dried under vacuum at $70{ }^{\circ} \mathrm{C} .{ }^{31} \quad 1,1,1,7,10,10$-Hexamethyltriethylenetetramine (HMTETA) (Aldrich, 97\%), trifluoroacetic acid (Aldrich, 99\%), triethylamine (Aldrich, 99\%), 2-bromoisobutyryl bromide (Aldrich, 98\%), acetone (Fluka, 99.5\%), diethyl ether (Riedel-de Haën, 99.5\%), sodium bicarbonate (sds, 99.5\%), sodium sulfate (Carlo Erba, 99\%), DOWEX MSC-H resin (Aldrich), neutral alumina $\left(\mathrm{Al}_{2} \mathrm{O}_{3}\right.$, Acros organics, 50-200 microns) were used as received. $\alpha$-Methoxy- $\omega$-hydroxy-poly (ethylene oxide) with $M_{\mathrm{w}}=5000 \mathrm{~g} \mathrm{~mol}^{-1}$ and $M_{\mathrm{w}} / M_{\mathrm{n}}=1.03$ $\left(\mathrm{CH}_{3}-\mathrm{PEG}_{113}-\mathrm{OH}\right)$ and $M_{\mathrm{w}}=2000 \mathrm{~g} \mathrm{~mol}^{-1}$ and $M_{\mathrm{w}} / M_{\mathrm{n}}=1.03$ $\left(\mathrm{CH}_{3}-\mathrm{PEG}_{45}-\mathrm{OH}\right)$ were obtained from Fluka and Aldrich, respectively, and used as received. Oligochitosan lactate with $M_{\mathrm{w}}<5000 \mathrm{~g} \mathrm{~mol}^{-1}$, poly(2-vinylpyridine) $\left(\mathrm{P}_{2} \mathrm{VP}\right)$ with $M_{\mathrm{w}}=$ $4111 \mathrm{~g} \mathrm{~mol}^{-1}$ and polyethylenimine (PEI) with $M_{\mathrm{w}}=700 \mathrm{~g} \mathrm{~mol}^{-1}$ were all purchased from Aldrich.

\section{(b) Synthesis of block copolymers}

PEO macroinitiator. A solution of $\alpha$-methoxy- $\omega$-hydroxypoly(ethylene oxide) $(100 \mathrm{~g}, 20 \mathrm{mmol})$ and triethylamine $(6.2 \mathrm{~mL}$, $44.4 \mathrm{mmol}$ ) in $300 \mathrm{~mL}$ of anhydrous THF was introduced in a $100 \mathrm{~mL}$ round-bottom flask equipped with a condenser and under argon or nitrogen atmosphere. 2-Bromoisobutyryl bromide $(17 \mathrm{~mL}, 137 \mathrm{mmol})$ was added drop wise and the solution was refluxed for $48 \mathrm{~h}$ under magnetic stirring. The 
solvent was then removed by rotary evaporation and $400 \mathrm{~mL}$ of dichloromethane was added. The resulting solution was washed with a saturated sodium bicarbonate aqueous solution and the organic phase was dried over anhydrous magnesium sulfate and filtered. The solution was concentrated by rotary evaporation and the PEO macroinitiator was recovered by precipitation in diethylether and dried under vacuum at room temperature (yield $=93 \%$ ), SEC in DMF: $M_{\mathrm{n}}=4800 \mathrm{~g} \mathrm{~mol}^{-1}, M_{\mathrm{w}} / M_{\mathrm{n}}=1.03$.

IR: $\nu / \mathrm{cm}^{-1} 1722(\mathrm{CO}), 1100\left(\mathrm{OCH}_{2}\right.$ ether groups from PEO chains), 526 (CBr).

NMR ${ }^{1} \mathrm{H}: \delta_{\mathrm{H}}\left(250 \mathrm{MHz} ; \mathrm{CDCl}_{3}\right), 1.9 \mathrm{ppm}(6 \mathrm{H}, \mathrm{s}$, OCOC $\left.\left(\mathrm{CH}_{3}\right)_{2} \mathrm{Br}\right), 3.4 \mathrm{ppm}\left(3 \mathrm{H}, \mathrm{s}, \mathrm{CH}_{3} \mathrm{OCH}_{2} \mathrm{CH}_{2}\right), 3.6 \mathrm{ppm}(448 \mathrm{H}$, br s, $\left.\mathrm{OCH}_{2} \mathrm{CH}_{2}\right)$ and $4.4 \mathrm{ppm}\left(2 \mathrm{H}, \mathrm{t}, \mathrm{CH}_{2} \mathrm{CH}_{2} \mathrm{OCOC}\left(\mathrm{CH}_{3}\right)_{2} \mathrm{Br}\right)$.

PEO-b-PtBuA. PEO macroinitiator ( $5 \mathrm{~g}, 0.97 \mathrm{mmol}, M=5150$ $\left.\mathrm{g} \mathrm{mol}^{-1}\right), \mathrm{CuBr}(0.07 \mathrm{~g}, 0.48 \mathrm{mmol}), \operatorname{HMTETA}(0.28 \mathrm{~g}, 1.2 \mathrm{mmol})$ and acetone $(20 \mathrm{~mL})$ were all placed in a $100 \mathrm{~mL}$ Schlenk flask. The reaction mixture was degassed by bubbling argon for 30 minutes. tert-Butyl acrylate $(5 \mathrm{~g}, 39 \mathrm{mmol})\left(M_{\mathrm{n}, \text { targeted }}=\right.$ $m_{\mathrm{tBuA}} / n_{\text {macroinitiator }}=5150 \mathrm{~g} \mathrm{~mol}^{-1}$ for the PtBuA block) was then transferred into the flask via an argon purged syringe. Polymerization was conducted for about 24 hours at $55^{\circ} \mathrm{C}$ under magnetic stirring. After completion of the polymerization, the green reaction mixture was diluted with $300 \mathrm{~mL}$ of THF and stirred for $48 \mathrm{~h}$ over $3.5 \mathrm{~g}$ of an ion exchange resin "DOWEX MSC-H" (more than 10 times excess of acid sites of resin against the initial amount of $\mathrm{CuBr}$ ). ${ }^{32}$ The resulting slightly yellow solution was finally filtered through a column packed with neutral alumina to remove the remaining traces of catalyst. The filtrate was concentrated by rotary evaporation. The polymer was precipitated into pentane and dried under vacuum at room temperature $(m=8.05 \mathrm{~g}$, yield $80.5 \%)$. SEC in DMF: $M_{\mathrm{n}}=7450 \mathrm{~g} \mathrm{~mol}^{-1}, M_{\mathrm{w}} / M_{\mathrm{n}}=1.03$.

IR: $\nu / \mathrm{cm}^{-1} 1722(\mathrm{CO}), 1390$ and $1364\left(\mathrm{OC}\left(\mathrm{CH}_{3}\right)_{3}\right), 1098$ $\left(\mathrm{OCH}_{2}\right.$ ether groups from PEO chains), $526(\mathrm{CBr})$.

NMR ${ }^{1} \mathrm{H}: \delta_{\mathrm{H}}\left(250 \mathrm{MHz} ; \mathrm{CDCl}_{3}\right), 1.15 \mathrm{ppm}(6 \mathrm{H}$, br s, OCOC $\left.\left(\mathrm{CH}_{3}\right)_{2}\right), 1.45 \mathrm{ppm}\left(369 \mathrm{H}\right.$, br s, $\left.\mathrm{CH}_{2} \mathrm{CHCOOC}\left(\mathrm{CH}_{3}\right)_{3}\right), 1.6 \mathrm{ppm}$ (82H, shoulder, $\left.\mathrm{CH}_{2} \mathrm{CHCOOC}\left(\mathrm{CH}_{3}\right)_{3}\right), 2.25 \mathrm{ppm}(41 \mathrm{H}$, br s, $\left.\mathrm{CH}_{2} \mathrm{CHCOOC}\left(\mathrm{CH}_{3}\right)_{3}\right), 3.4$ ppm (3H, s, $\left.\mathrm{CH}_{3} \mathrm{OCH}_{2} \mathrm{CH}_{2}\right), 3.7$ ppm $\left(448 \mathrm{H}\right.$, br s, $\left.\mathrm{OCH}_{2} \mathrm{CH}_{2}\right)$ and $4.2 \mathrm{ppm}(2 \mathrm{H}$, br s, $\left.\mathrm{CH}_{2} \mathrm{CH}_{2} \mathrm{OCOC}\left(\mathrm{CH}_{3}\right)_{2}\right)$.

PEO-b-PAA. In a $100 \mathrm{~mL}$ Schlenk flask, trifluoroacetic acid (3.15 mL, $40.9 \mathrm{mmol})$ was slowly added to a solution of PEO- $b$ $\operatorname{PtBuA}\left(M_{\mathrm{n}, \mathrm{SEC}}=7450 \mathrm{~g} \mathrm{~mol}^{-1}, 1 \mathrm{~g}, 0.13 \mathrm{mmol}, 2.4 \mathrm{mmol}\right.$ of tBuA units) in $2.1 \mathrm{~mL}$ of anhydrous dichloromethane at $0{ }^{\circ} \mathrm{C}$. The reaction mixture was kept under magnetic stirring at this temperature for one hour and then for 48 hours at room temperature. The crude product was precipitated in diethyl ether and the copolymer was recovered by centrifugation at $6000 \mathrm{rpm}$ for 30 minutes. The copolymer was washed with diethylether four times and finally dried under vacuum. The yellowish white product was re-dissolved in water for purification by freezedrying eliminating the last traces of reactant (yield $>95 \%$ ).

IR: $\nu / \mathrm{cm}^{-1} 1722(\mathrm{CO}), 1550(\mathrm{COO}-), 1098\left(\mathrm{OCH}_{2}\right.$ ether groups from $\mathrm{PEO}$ chains), $526(\mathrm{CBr})$.

NMR ${ }^{1} \mathrm{H}$ : $\delta_{\mathrm{H}}\left(250 \mathrm{MHz}\right.$; DMSO-d $\left.{ }^{6}\right), 1.1 \mathrm{ppm}(6 \mathrm{H}, \mathrm{t}$, OCOC $\left.\left(\mathrm{CH}_{3}\right)_{2}\right), 1.5 \mathrm{ppm}\left(82 \mathrm{H}\right.$, br s, $\left.\mathrm{CH}_{2} \mathrm{CHCOOH}\right), 2.3 \mathrm{ppm}(41 \mathrm{H}$, br s, $\left.\mathrm{CH}_{2} \mathrm{CHCOOH}\right), 3.25 \mathrm{ppm}\left(3 \mathrm{H}, \mathrm{s}, \mathrm{CH}_{3} \mathrm{OCH}_{2} \mathrm{CH}_{2}\right), 3.5 \mathrm{ppm}(448 \mathrm{H}$, br s, $\left.\mathrm{OCH}_{2} \mathrm{CH}_{2}\right)$ and 4.05 ppm $\left(2 \mathrm{H}\right.$, br s, $\left.\mathrm{CH}_{2} \mathrm{CH}_{2} \mathrm{OCOC}\left(\mathrm{CH}_{3}\right)_{2}\right)$.
Preparation of micelle suspensions. Aqueous PEO- $b$-PAA diblock copolymer solutions were mixed with aqueous solutions of oligochitosan according to a charge mixing ratio $R$ equal to 1 . The mixing ratio was defined as the number of acrylic acid units added against the number of amine functions added in the mixture $\left(R=n_{\mathrm{AA}} / n_{\mathrm{N}}\right)$. The $\mathrm{DHBC}$ concentration was kept constant at 2.5 weight $\%$, whatever the molecular weight of the copolymer. When the $\mathrm{pH}$ effect on micelle formation was studied, a solution of copolymer was first mixed with a solution of polyamine; the $\mathrm{pH}$ of the mixture was fixed at 2 and then, the $\mathrm{pH}$ was increased by adding small amounts of a $0.5 \mathrm{M} \mathrm{NaOH}$ solution. Small amounts of a $0.5 \mathrm{M} \mathrm{HNO}_{3}$ solution were added for decreasing the $\mathrm{pH}$ when the reversibility of the micellization process was studied. The DLS analysis was done directly on the mixture between each addition of base and after a vigorous stirring for five minutes. The same procedure was followed with copolymers of different block lengths in order to study the influence of the DHBC symmetry degree on micelle formation.

The effect of ionic strength was investigated by DLS with a solution of PEO113- $b$-PAA33 and oligochitosan, whose $\mathrm{pH}$ was adjusted to 6 . The ionic strength was increased by adding known amounts of $\mathrm{NaCl}$ salt directly in the solution.

\section{(c) Characterization}

${ }^{1} \mathrm{H}$ NMR spectra of PEO- $b$-PtBuA polymers were recorded in $\mathrm{CDCl}_{3}$ at room temperature with a Bruker $250 \mathrm{MHz}$ spectrometer. In the case of PEO- $b$-PAA copolymers, DMSO- $\mathrm{d}^{6}$ was used as the solvent.

Size exclusion chromatography (SEC) was performed in DMF

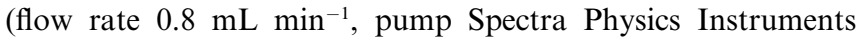
SP8810 with two columns mixed-C PL-gel $5 \mu \mathrm{m}$ from Polymer Laboratories thermostated at $70{ }^{\circ} \mathrm{C}$ and a refractive index detector Shodex Rise-61). PEO standards with $M_{\mathrm{n}}$ ranging from 194 to $120000 \mathrm{~g} \mathrm{~mol}^{-1}$ were used for calibration.

Dynamic light scattering measurements were carried out with an Autosizer 4800 instrument (Malvern, UK) with a $10 \mathrm{~mW}$ laser operating at $532 \mathrm{~nm}$. Hydrodynamic diameters were obtained from measured diffusion coefficients by using the Stokes-Einstein equation. The Contin algorithm was used for determining intensity-averaged hydrodynamic diameters.

Transmission electron microscopy (TEM) experiments were performed on a Jeol 1200 EXII microscope operated at $80 \mathrm{kV}$. A drop of micelle solution was deposited onto a TEM precoated grid and the samples were air dried. A staining solution of uranyl acetate $2 \mathrm{wt} \%$ was used for the preparation of grids with negative staining. After the drops of micelle solution were dried, a drop of staining solution was put in contact with the sample for $1 \mathrm{~min}$. The excess was wicked away with filter paper.

Capillary Electrophoresis (CE) was carried out with an Agilent Technologies system (Waldbronn, Germany) equipped with a diode array detector. Separation capillaries prepared from bare silica tubing were purchased from Composite Metal Services (Worcester, UK). Fused silica capillary dimensions were $50 \mu \mathrm{m}$ i.d. $\times 58.5 \mathrm{~cm}$ (effective length to the detector, $50 \mathrm{~cm}$ ). Electrolytes used for indirect UV detection were $12 \mathrm{mM}$ 2-amino-2methyl-1,3-propanediol (ammediol) and $6 \mathrm{mM}$-anisic acid at $\mathrm{pH}=8.8$. Electrolytes used for the measurement of the sensitivity of detection of the chromophore ( $p$-anisic acid) by direct UV 
detection were $12 \mathrm{mM}$ ammediol and $6 \mathrm{mM}$ acetic acid at $\mathrm{pH}=$ 8.8. The separations were performed at $+20 \mathrm{kV}$. Samples were injected hydrodynamically at 17 mbar for $5 \mathrm{~s}$ followed by a 10 mbar, $3 \mathrm{~s}$ injection of the electrolyte. Sample concentration ranges were $2-10 \mathrm{~g} \mathrm{~L}^{-1}$ in water for PEO45- $b$-PAA9 and PEO113- $b$-PAA18 and $1-5 \mathrm{~g} \mathrm{~L}^{-1}$ in water for PEO45- $b$-PAA64. UV detection was performed at $248 \mathrm{~nm}$. Temperature of the experiment was set at $25^{\circ} \mathrm{C}$.

Small Angle X-ray Scattering (SAXS) measurements were performed in transmission configuration on a Bruker DXPA (Nanostar), using a copper anode $(40 \mathrm{kV}, 35 \mathrm{~mA})$ as X-ray source. A two mirror optic was used to select the wave length of copper $(\lambda=1.54 \AA)$. A "Histar" 2-D detector $(22 \times 22 \mathrm{~cm})$ from Bruker was used at $1 \mathrm{~m}$ distance from the sample. Samples were filled in glass capillaries. The resulting 2-D images were found isotropic, and the data were azimuthally averaged to yield scattering curves of the intensity corrected from the background from a solvent capillary, versus the scattering vector $q$. Gyration radii $\left(R_{\mathrm{g}}\right)$ were determined by the Guinier approximation on the scattering vector value domain comprised between $0.01 \AA^{-1}$ and $0.04 \AA^{-1}$ (the Guinier domain). The formula used was the following: $I(q) \approx \exp \left(-q^{2} R_{\mathrm{g}}{ }^{2} / 3\right)$ where $I$ and $q$ are the scattered $\mathrm{X}$-ray intensity and the absolute value of the scattering vector, respectively. $R_{\mathrm{g}}$ was then measured from the slope of the linear part of the $\log (I)$ as a function of $q^{2}$ representation.

\section{Results and discussion}

\section{(a) Synthesis of PEO-b-PAA block copolymers}

The different steps for the synthesis of the PEO- $b$-PAA DHBC copolymers are summarized in Scheme 1.

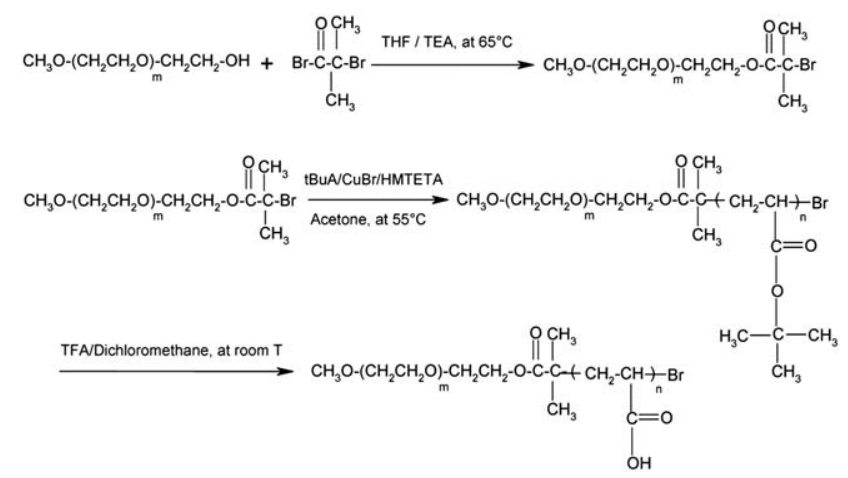

Scheme 1 Synthesis of the PEO macroinitiator followed by the synthesis of PEO- $b$-PtBuA and its hydrolysis to yield PEO- $b$-PAA copolymer.
PEO macroinitiator. The PEO macroinitiator was synthesized by modifying the hydroxyl extremity of $\alpha$-methoxy- $\omega$-hydroxypoly(ethylene oxide) according to a procedure adapted from Ranger et al. ${ }^{33}$ Esterification of this hydroxyl function with 2bromoisobutyryl bromide leads to the macroinitiator formation. This macroinitiator contains an activated alkyl bromide moiety, which is suitable as an effective initiator for the ATRP of tertbutyl acrylate monomer as the second block. The bromide functionality of the PEO macroinitiator was investigated by ${ }^{1} \mathrm{H}$ NMR (Fig. S1 $\dagger$ ). The appearance of a signal at $4.35 \mathrm{ppm}$ with an integration corresponding to 2 protons is assigned to the methylene of the ester function of the PEO macroinitiator. Moreover, the existence of a $6 / 2$ ratio between the integrations of the methyl protons $-\mathrm{C}\left(\mathrm{CH}_{3}\right)_{2} \mathrm{Br}$ at $1.92 \mathrm{ppm}$ and the methylene protons at $4.35 \mathrm{ppm}$ proves that each $\mathrm{PEO}$ chain contains a $-\mathrm{Br}$ end-group. IR also highlights the formation of the macroinitiator by showing the characteristic peak of the ether units at $1100 \mathrm{~cm}^{-1}$ associated with the characteristic peak of the $\mathrm{C}-\mathrm{Br}$ bond at $526 \mathrm{~cm}^{-1}$ and a very small characteristic peak of the $\mathrm{C}=\mathrm{O}$ bond at $1722 \mathrm{~cm}^{-1}$

PEO-b-PtBuA. As illustrated in Scheme 1, PEO- $b$-PtBuA copolymers were obtained by ATRP of tert-butyl acrylate in acetone at $55{ }^{\circ} \mathrm{C}$ initiated by the PEO macroinitiator in the presence of $\mathrm{CuBr} / \mathrm{HMTETA}$ complex as catalyst. The procedure was adapted from the work of Kelly and Matyjaszewsky. ${ }^{34} \mathrm{~A}$ typical ${ }^{1} \mathrm{H}$ NMR spectrum of a PEO- $b$-PtBuA is given in the ESI (Fig. S2 $\dagger$ ). The signals at $1-2.5 \mathrm{ppm}$ and $3.5-3.7 \mathrm{ppm}$ due to the protons of the PtBA and PEO blocks respectively were all detected. The shift of the peak assigned to the isobutyryl protons from $1.9 \mathrm{ppm}$ on the PEO macroinitiator spectrum to $1.15 \mathrm{ppm}$ on the copolymer spectrum is consistent with a quantitative initiation. Thus, ${ }^{1} \mathrm{H}$ NMR analysis highlights the formation of the diblock copolymer.

By varying the amount of $\mathrm{tBuA}$ monomer in the reaction medium, copolymers with various molecular weights have been synthesized from the same PEO macroinitiator. Molecular weights of copolymers measured by SEC analyses and calculated from the ${ }^{1} \mathrm{H}$ NMR analyses are given in Table 1 .

As shown in Table 1, experimental molecular weights calculated from the ${ }^{1} \mathrm{H}$ NMR spectra are very close to the theoretical molecular weights of the copolymers, demonstrating that the polymerization of tBuA took place as expected. These results, together with the narrow polydispersity of the molecular weight distribution of the copolymers $\left(M_{\mathrm{w}} / M_{\mathrm{n}}<1.05\right)$, prove the good control of the polymerization. In Fig. 2, the shift of the molecular weight distribution toward higher molecular weight is consistent with the increase of the PtBuA block length in this series. The

Table 1 Molecular weights of PEO- $b$-PtBuA copolymers

\begin{tabular}{lccccc}
\hline Copolymer & $M_{\mathrm{n}, \text { targeted }}{ }^{a}$ & $\mathrm{DP}_{n, \mathrm{PtBuA}}{ }^{b}(\mathrm{NMR})$ & $M_{\mathrm{n}}{ }^{b}(\mathrm{NMR})$ & $M_{\mathrm{n}}{ }^{c}(\mathrm{SEC})$ & 5670 \\
1 & 6040 & 8 & 6150 & 6100 & 1.02 \\
2 & 6930 & 16 & 7260 & 6620 & 1.03 \\
3 & 8260 & 24 & 10390 & 7450 & 1.03 \\
4 & 10300 & 41 & & $M_{\mathrm{n}}(\mathrm{SEC})$
\end{tabular}

${ }^{a} M_{\mathrm{n} \text {,targeted }}=M_{\mathrm{n} \text {,macroinitiator }}+m_{\mathrm{tBuA}} / n_{\text {macroinitiator }}{ }^{b}$ Calculated from the ${ }^{1} \mathrm{H}$ NMR spectrum by $\mathrm{DP}_{n, \mathrm{PtBuA}(\mathrm{NMR})}=\left(I_{1} / 12\right) /\left(I_{2} /(113 \times 4+3)\right) . I_{1}$ is the integration of the peaks in the range of $1.2-2.3 \mathrm{ppm}$ and $I_{2}$ is the integration of the peaks in the range of $3.44 \mathrm{ppm} . M_{\mathrm{n}, \mathrm{NMR}}=M_{\mathrm{n}, \mathrm{macroinitiator}}+$ $\mathrm{DP}_{n, \mathrm{PtBuA}(\mathrm{NMR})} \times M_{\mathrm{tBuA}}$ with $M_{\mathrm{n} \text {,macroinitiator }}=5150 \mathrm{~g} \mathrm{~mol}^{-1}$ and $M_{\mathrm{tBuA}}=128 \mathrm{~g} \mathrm{~mol}^{-1}{ }^{c}$ SEC in DMF (with PEO calibration). 


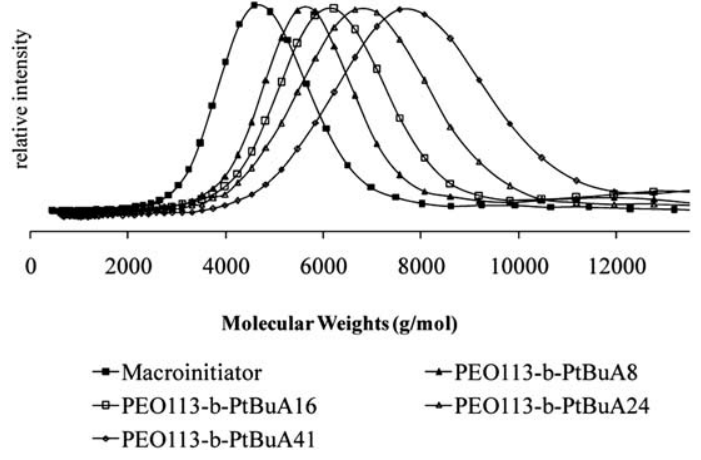

Fig. 2 SEC of PEO macroinitiator and PEO- $b$-PtBuA copolymers (values in brackets indicate the $\mathrm{DP}_{n}$ determined by ${ }^{1} \mathrm{H} \mathrm{NMR}$ ).

discrepancy between $M_{\mathrm{n}, \mathrm{NMR}}$ and $M_{\mathrm{n}, \mathrm{SEC}}$ could be ascribed to the lack of appropriate standards for such block copolymers.

PEO-b-PAA. The hydrolysis procedure is outlined in Scheme 1. tert-Butyl ester moieties were removed by an acidic hydrolysis using trifluoroacetic acid in dichloromethane according to a procedure adapted from the work of Hou et al. ${ }^{35}$ Completion of the hydrolysis was checked by ${ }^{1} \mathrm{H}$ NMR analysis. In DMSO- ${ }^{6}$, the ${ }^{1} \mathrm{H}$ NMR signal at $\delta=1.4 \mathrm{ppm}$ of the tert-butyl group $(-\mathrm{C}$ $\left.\left(\mathrm{CH}_{3}\right)_{3}\right)$ in the tert-butyl acrylate units $\left(-\mathrm{CH}_{2}-\mathrm{CH}(\mathrm{COOC}\right.$ $\left.\left.\left(\mathrm{CH}_{3}\right)_{3}\right)^{-}\right)$is well separated from the signal of the ethylene oxide units $\left(-\mathrm{O}-\mathrm{CH}_{2}-\mathrm{CH}_{2}-, \delta=3.5 \mathrm{ppm}\right)$. The disappearance of the peak assigned to the tert-butyl group $(\delta=1.4 \mathrm{ppm})$ was the proof of the end of the reaction (Fig. S $3 \dagger$ ).

The quantitative removal of copper ions from the copolymers was ascertained by atomic absorption spectroscopy (molar ratio $[\mathrm{Cu}] /[\mathrm{AA}]<10^{-4}$ ).

Theoretical molecular weights as well as molecular weights determined by ${ }^{1} \mathrm{H}$ NMR and titration of the synthesized copolymers are given in Table 2 .

An important question was to know if the acidic hydrolysis would not break the ester linkage between the two blocks. Elements of answer have been provided by ${ }^{1} \mathrm{H}$ NMR. Indeed, on the ${ }^{1} \mathrm{H}$ NMR spectrum (Fig. S3†), the fact that the signal at 4.2 ppm corresponding to the methylene adjacent to the ester function is still present on the PEO- $b$-PAA spectrum is a proof that the ester linkage still exists. Moreover, the integrations of this signal $-\mathrm{CH}_{2} \mathrm{CH}_{2} \mathrm{OC}(\mathrm{O}) \mathrm{C}\left(\mathrm{CH}_{3}\right)_{2}-$ at $4.2 \mathrm{ppm}$ and the signal at 1.1 ppm corresponding to the isobutyrate protons $-\mathrm{CH}_{2} \mathrm{CH}_{2} \mathrm{OC}(\mathrm{O})$
$\mathrm{C}\left(\mathrm{CH}_{3}\right)_{2}-$ were determined. The ratio of these two integrations is still equal to $2 / 6$, indicating that the ester linkage between the two blocks was quantitatively preserved.

Finally, the poly(acrylic acid) chains of the PEO- $b$-PAA copolymers have been methylated in order to analyze the polymers by SEC in DMF. The absence of any isolated peak corresponding to PEO and poly(methyl acrylate) homopolymer chains on the SEC spectra confirmed that no significant degradation of the blocky structure of the copolymer occurred during hydrolysis with TFA. All these results are in accordance with those found by Hou et al. ${ }^{35}$ and Guillemet ${ }^{36}$ who demonstrated that the ester linkage of similar copolymers resisted to higher TFA concentrations than ours. It also agrees with other studies involving TFA for the selective cleavage of carboxylic esters in mild conditions. ${ }^{37,38}$

Three typical copolymers either rich in PEO (PEO113- $b$ PAA18) or rich in PAA (PEO45- $b$-PAA64) and another one presenting a very short PAA segment (PEO45- $b$-PAA9) were also characterized by capillary electrophoresis (CE). In a previous work, Anik et al. ${ }^{29}$ showed that it was possible to use $\mathrm{CE}$ for characterizing the macromolecular architecture of copolymers by the determination of the copolymer effective charge densities. In this previous CE study, the effective charge densities $\left(f_{\text {eff }}\right)$ of diblock and statistic copolymers were determined via the measurement of the sensitivity of detection of the copolymer in indirect UV detection mode. ${ }^{29}$ Experimental results were favorably compared to the Manning theory of counterion charge condensation. ${ }^{39}$ In a few words, Manning limiting laws of counterion condensation predict that, in the case of an infinitely long rigid rod polyion, a fraction of counterions is electrostatically bound (or condensed in solution) to the polyion, reducing the chemical charge density $(f$ being the molar fraction of charged monomers) into an effective charge density $\left(f_{\text {eff }}\right)$. For a statistical vinylic copolymer, Manning theory predicts that $f_{\text {eff }}=f$ for $f<0.36$ (no counterion condensation) and $f_{\text {eff }}=0.36$ for $f>0.36$ (counterion condensation). For a diblock copolymer with a neutral block and a charged vinylic block, the effective charge is given by $f_{\text {eff }}=0.36 \times f$, for all $f$ values. Therefore, for a given $f$ value, there is a difference in the effective charge between a statistical and a diblock copolymer. Reversely, the comparison between the experimental $f_{\text {eff }}$ values and the $f$ values can bring valuable information on the macromolecular architecture (i.e. on the repartition of the charged monomers in the chain).

Table 2 Molecular weights of PEO- $b$-PAA copolymers

\begin{tabular}{|c|c|c|c|c|}
\hline Copolymer & $M_{\mathrm{n}}^{a}$ (theoretical) & $M_{\mathrm{n}}^{b}(\mathrm{NMR})$ & $M_{\mathrm{n}}^{c}$ (titration) & $\begin{array}{l}\text { Used } \\
\text { code }^{d}\end{array}$ \\
\hline $1^{\prime}$ & 5730 & 5510 & 5830 & PEO113- $b$-PAA9 \\
\hline $3^{\prime}$ & 6880 & 6250 & 6730 & PEO113- $b$-PAA22 \\
\hline $4^{\prime}$ & 8100 & 7750 & 7520 & PEO113- $b$-PAA33 \\
\hline $5^{\prime}$ & 2800 & 2750 & 2800 & PEO45-b-PAA9 \\
\hline $6^{\prime}$ & 6760 & 6660 & 6790 & PEO45- $b$-PAA64 \\
\hline
\end{tabular}




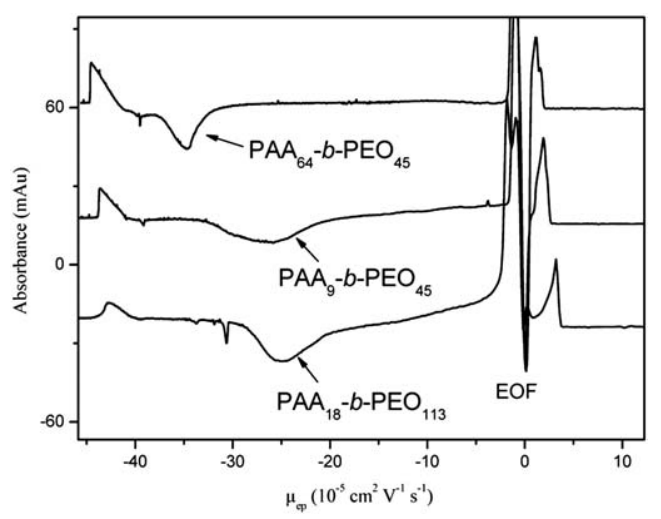

Fig. 3 Effective mobility-scale electropherograms obtained for PEO- $b$ PAA copolymers using indirect UV detection mode. EOF: electroosmotic flow.

Experimental values of effective charge densities $\left(f_{\text {eff }}\right)$ of copolymers PEO113- $b$-PAA18, PEO45- $b$-PAA9 and PEO45- $b$ PAA64 were determined using this recently described methodology. ${ }^{29}$ The superposition of the effective mobility-scale electropherograms obtained by indirect UV detection for the three copolymers is given in Fig. 3. Chemical charge densities $f$ of these copolymers vary from $13 \%$ for PEO113-b-PAA 18 to $58 \%$ for PEO45-b-PAA64 (Table 3). Negative peaks indicated with arrows are detected in the background electrolyte containing anisate chromophore and ammediol counterion for indirect UV detection at $254 \mathrm{~nm}$. The first observation is that, as expected, the effective electrophoretic mobility of the copolymer solute $\left(\mu_{\mathrm{S}}\right)$ increases with the chemical charge density $f$. Experimental effective charge densities $\left(f_{\text {eff }}\right)$ were calculated from the chemical charge density $f$ and from the effective charge per charged monomer $z_{1}$ according to the following relation: ${ }^{29}$

$$
f_{\text {eff }}=f \times z_{1}
$$

$z_{1}$ is experimentally related to the sensitivity of detection of the copolymer solute and to the effective mobilities of the chromophore $\left(\mu_{\mathrm{A}}\right)$, solute $\left(\mu_{\mathrm{S}}\right)$, and counter-ion $\left(\mu_{\mathrm{C}}\right)$ by the relation:

$$
Z_{1}=\frac{1}{k_{\mathrm{A}}} \frac{\alpha_{\mathrm{S}}}{\alpha_{\mathrm{A}}}
$$

where $k_{\mathrm{A}}$ is the mobility ratio:

$$
k_{\mathrm{A}}=\frac{\mu_{\mathrm{A}}\left[\mu_{\mathrm{S}}+\mu_{\mathrm{C}}\right]}{\mu_{\mathrm{S}}\left[\mu_{\mathrm{A}}+\mu_{\mathrm{C}}\right]}
$$

$\alpha_{\mathrm{S}}$ is the slope of the calibration plot of the solute in indirect UV detection mode and $\alpha_{\mathrm{A}}$ is the slope of the calibration plot of the probe determined by direct UV detection at the same detection wavelength than that used for the solute calibration. Calibration plots are given in the ESI (Fig. S4 $\uparrow$ ). The ratio $\alpha_{\mathrm{S}}$ against $\alpha_{\mathrm{A}}$ is the transfer ratio (TR). It is related to the ability of the solute to displace the probe and is defined as the number of mole of the probe displaced by mole of solutes. All experimental values are listed in Table 3.

As shown in Table 3, there is a very good agreement between the experimental and theoretical $f_{\text {eff, theo }}$ (Manning) values for the three copolymers. This result confirms without any ambiguity the diblock architecture of the synthesized copolymers. Moreover, the variation of experimental mobility values found by $\mathrm{CE}$ as a function of the chemical charge density $f$ (determined from titration) highlights the efficiency of our synthesis strategy for controlling the PAA block length of DHBCs. Another key result is that about $60 \%$ of the sodium counter-ions of the polyelectrolyte block are condensed on the polyion, which is consistent with the PIC micelle formation triggered by the counter-ions release.

\section{(b) Complex micelle formation}

In dilute aqueous solution, interactions between ionic-neutral DHBC and oppositely charged polyelectrolytes lead to the formation of PIC micelles, which present a nanostructure similar to that of micelles of classical amphiphilic copolymers. But, while in PIC micelles, the attractive interactions responsible for the core formation are electrostatic, they are hydrophobic interactions in classical amphiphilic systems, where a strong segregation occurs between the two copolymer blocks. This difference leads to differences in their behaviour in aqueous solution. Here, the electrostatic polyion complex system that has been used as a reversible structure directing agent of mesoporous silica is investigated. It results from the complexation between two weak polyelectrolytes: a neutral-weak polyacid DHBC (PEO-b-PAA) and a weak polybase (oligochitosan).

pH range of micellization. The PEO113-b-PAA33 block copolymer was mixed with oligochitosan in aqueous solution, at a fixed ratio $R=1$; and the behaviour of the mixture was studied from $\mathrm{pH} 2$ to 10. Fig. 4 shows the variations of the light scattered intensity of the suspension and of the polydispersity index (PDI) of the objects as a function of the $\mathrm{pH}$. The scattered intensity has a low value at low $\mathrm{pH}$ and at high $\mathrm{pH}$ and goes through a strong maximum at $\mathrm{pH}=6$. At that $\mathrm{pH}$, the intensity is about 10 times higher than the smallest value obtained at high $\mathrm{pH}$. On the intermediate $\mathrm{pH}$ domain, approximately comprised between 5 and 7 , the high value of the light scattered intensity reflects the

Table 3 Values of chemical charge density $(f)$, detection sensitivity of solute $\left(\alpha_{\mathrm{S}}\right)$ and probe $\left(\alpha_{\mathrm{A}}\right)$, effective electrophoretic mobility (in absolute value) of

\begin{tabular}{|c|c|c|c|c|c|c|c|c|c|c|c|}
\hline Copolymers & $f$ & $\alpha_{\mathrm{S}}^{a}$ & $\alpha_{\mathrm{A}}{ }^{a}$ & TR & $\mu_{\mathrm{A}}{ }^{b}$ & $\mu_{\mathrm{S}}^{b}$ & $\mu_{\mathrm{C}}^{b}$ & $k_{\mathrm{A}}$ & $z_{1}$ & $f_{\mathrm{eff}^{c}}^{c}$ & $f_{\text {eff,theo }}$ \\
\hline PEO45- $b$-PAA9 & 0.16 & 2.61 & 7.86 & 0.33 & 28.86 & 27.86 & 28.37 & 1.01 & 0.32 & $0.054 \pm 0.002$ & 0.059 \\
\hline
\end{tabular}
probe $\left(\mu_{\mathrm{A}}\right)$, solute $\left(\mu_{\mathrm{S}}\right)$, and counter-ion $\left(\mu_{\mathrm{C}}\right)$, transfer ratio (TR), mobility ratio $\left(k_{\mathrm{A}}\right)$, experimental effective charge per monomer $\left(z_{1}\right)$, effective charge density $\left(f_{\text {eff }}\right)$ and theoretical effective charge density $\left(f_{\text {eff,theo }}\right)$ for diblock copolymers

${ }^{a}$ In $\mathrm{mAu} \mathrm{L} \mathrm{mol}{ }^{-1} \cdot{ }^{b} \mathrm{In} 10^{-5} \mathrm{~cm}^{2} \mathrm{~V}^{-1} \mathrm{~s}^{-1}$. ${ }^{c}$ Standard errors calculated from the linear fit using the Origin software. 


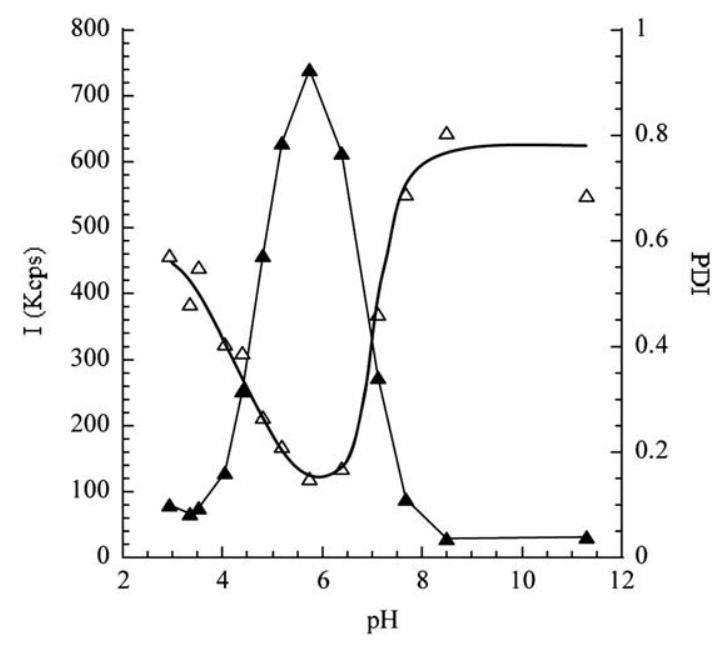

Fig. 4 Scattered intensity (full triangles) and polydispersity index (empty triangles) of an aqueous mixture of PEO113-b-PAA33/oligochitosan as a function of $\mathrm{pH}$.

formation of polymer aggregates of high molecular weight. The sharp decrease of the PDI from 0.55 to 0.13 , associated with this intensity variation, accounts for the change from a polymodal to a unimodal population of scattering objects monodisperse in size. In comparison, in the case of the copolymer and oligochitosan studied individually, no intensity variation is observed (Fig. S5 $†$ ): the scattered intensity values remain low on the whole $\mathrm{pH}$ range. These results highlight that, on an intermediate $\mathrm{pH}$ range, the polymer mixture leads to the formation of micelles, resulting from complexation between PAA blocks and oligochitosan.

Since the $\mathrm{pH}$ has an effect on the ionization degree of weak polyelectrolytes, the dependence of ionization degrees of the PAA block and of oligochitosan on $\mathrm{pH}$ has been studied (Fig. S6†). Acido-basic titrations of PEO113-b-PAA33 copolymers and oligochitosan, individually, allowed determination of $\mathrm{p} K_{\mathrm{a}} \mathrm{s}$ of each polymer (6.2 for the polyacid, 6.5 for the polybase). Then, degrees of ionization were calculated based on the $\mathrm{p} K_{\mathrm{a}}$ values. It should be considered that upon polymer mixing, the ionization degrees of each polyelectrolyte are influenced by the presence of the other polyelectrolyte. Curves shown for individual polymers (Fig. S6†) are hence representative of the ionization degrees of the polymers before mixing. The existence of a $\mathrm{pH}$ domain where the degrees of ionization of PAA and oligochitosan chains are both high is evidenced. This critical $\mathrm{pH}$ domain corresponds to the experimentally observed $\mathrm{pH}$ range of micelle formation, as evidenced in Fig. 4. We conclude that micelle formation is favored when the two polyelectrolytes are both predominantly charged, as illustrated in Fig. 1. The present results are in line with those found in the literature in the case of complex systems between two weak polyelectrolytes, with at least one of the two being a DHBC. Gohy et al., who studied complexation of poly(ethylene oxide)- $b$-poly(2-vinylpyridinium) with poly(ethylene oxide)- $b$-poly(sodium methacrylate), observed that micelles formed in $\mathrm{pH}$ domains between 2 and 6.1. ${ }^{19}$ Voets et al. showed that complex micelles formed in the 6.2-8.7 $\mathrm{pH}$ range with the system composed of the poly(4-(2amino hydrochloride-ethylthio)butylene)-b-poly(ethylene oxide)
(PAETB49- $b$-PEO212) and poly(4-(2-sodium carboxylate-ethylthio)butylene)- $b$-poly(ethylene oxide) (PCETB47- $b$-PEO212). ${ }^{40}$

The reversibility of the micellization process as a function of the $\mathrm{pH}$ was also studied by dynamic light scattering. Fig. 5 shows the change of the light scattered intensity with a cyclic variation of the $\mathrm{pH}$ in the case of the PEO113-b-PAA33/oligochitosan mixture (stoichiometric mixture in ionisable units, $R=1$ ). Initially, a gradual increase of $\mathrm{pH}$ from 2.8 to 11.5 is performed; the scattered intensity variation is then similar to the one observed in Fig. 4: monodisperse scattering objects with hydrodynamic diameters ranging from 30 to $35 \mathrm{~nm}$ are formed at $\mathrm{pH}$ about 6 . Once the $\mathrm{pH}$ reaches 11.5 , the $\mathrm{pH}$ of the same solution is gradually lowered back down to 3.1. During the $\mathrm{pH}$ decrease, micelles form again, as evidenced by the increased intensity between $\mathrm{pH} 6.5$ and 3.5. Interestingly, the $\mathrm{pH}$ domain of micelle formation when $\mathrm{pH}$ decreases is wider than the $\mathrm{pH}$ domain obtained when the $\mathrm{pH}$ is increased. The presence of micelles is observed at lower $\mathrm{pH}$ values: micelles are still present at $\mathrm{pH} 4$, as evidenced by the high intensity at this $\mathrm{pH}$. Moreover, the hydrodynamic diameters of micelles present, in the $\mathrm{pH}$ decrease run, are slightly larger $\left(D_{\mathrm{hmax}}=36.5 \mathrm{~nm}\right.$ at $\left.\mathrm{pH}=4.5\right)$ than those measured when $\mathrm{pH}$ is increased $\left(D_{\mathrm{hmax}}=31 \mathrm{~nm}\right.$ at $\left.\mathrm{pH}=5.6\right)$. The larger $D_{\mathrm{h}}$ values might be explained by the increase of ionic strength due to the addition of $\mathrm{NaOH}$ and then $\mathrm{HNO}_{3}$ used for varying the $\mathrm{pH}$. Indeed, monovalent counter-ions added such as $\mathrm{Na}^{+}$and $\mathrm{NO}_{3}{ }^{-}$partially screen polyion charges during micelle formation leading to less compact electrostatic complexes in micelle cores. Moreover, as these counter-ions are accompanied of water molecules present in their coordination spheres, micelle cores under formation are certainly more hydrated than when micelles are formed during the $\mathrm{pH}$ rise, at lower ionic strength. More swollen complex cores may hence be obtained during the $\mathrm{pH}$ decrease. Moreover, it is interesting to underline the high stability at low $\mathrm{pH}$ of priorly formed micelles: micelles are quite stable at acidic $\mathrm{pH}$, down to 3.5 (at a $\mathrm{pH}$ much lower than the $\mathrm{p} K_{\mathrm{a}}$ of the polyacid), when they have been priorly formed at a higher $\mathrm{pH}$. This may be partly due to the formation of

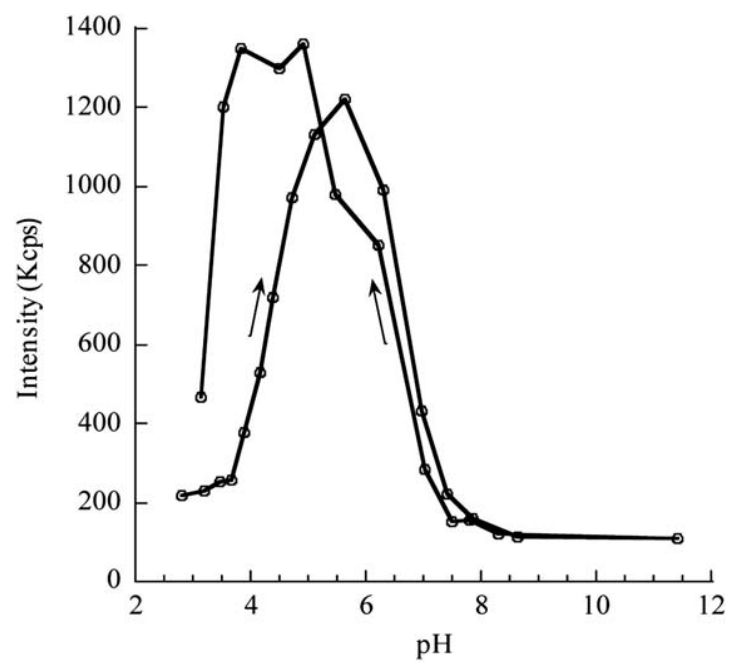

Fig. 5 Scattered intensity variation as a function of $\mathrm{pH}$ for an aqueous mixture of PEO113-b-PAA33 and oligochitosan. First, $\mathrm{pH}$ is increased up to 11.5 , then, it is decreased back down to 3.5 . 
intramicellar hydrogen bonds between polymer chains upon decreasing the $\mathrm{pH}$.

Corona PEO chains are at a higher volume concentration within the micelle (i.e. during the decrease of $\mathrm{pH}$ ) than when isolated in solution (i.e. during the increase of $\mathrm{pH}$ ), this favours hydrogen bonds when decreasing the $\mathrm{pH}$ below 5 . Intramicellar hydrogen bonding may, then, impede or slow down the micelle dissociation process that should occur upon polyacid neutralization. It leads to a hysteresis of stability at low $\mathrm{pH}$ probably due to intramicellar hydrogen bonding that occurs when $\mathrm{pH}$ is decreased down to acidic medium.

Size and structure of the micelles. From the diffusion coefficient $D_{0}$ determined by DLS, the value of the hydrodynamic diameter $D_{\mathrm{h}}$ was calculated to be $30 \mathrm{~nm}$ at $\mathrm{pH}=6$ where the intensity is maximal. As revealed by TEM images with and without negative staining (Fig. 6(a) and (c)), the complex micelles obtained at $\mathrm{pH}=6$ are isotropic. The histogram analysis of the size distribution obtained from the negative staining TEM image (Fig. 6(a) and (b)) allows determining an average diameter of $32 \mathrm{~nm}$. The image obtained without negative staining (Fig. 6(c)) reveals the internal structure of the aggregates. An electronically dense core composed of the polyion complex (appearing in dark) is surrounded by a more diffuse corona of the PEO chains (appearing as a clearer corona around the core). ${ }^{41}$

This core-corona nanostructure was confirmed by SAXS. Fig. 7 shows the X-ray scattered intensity plotted as a function of $q$, the amplitude of the scattering vector. The slope in the intermediate $q$-range accounts for the shape and structure of the core of the object. The sharp decrease of the intensity with a power law behaviour $I(q) \propto q^{-4}$ in this $q$-range suggests a structure constituted of a well defined core, presenting an abrupt interface with the surrounding corona.
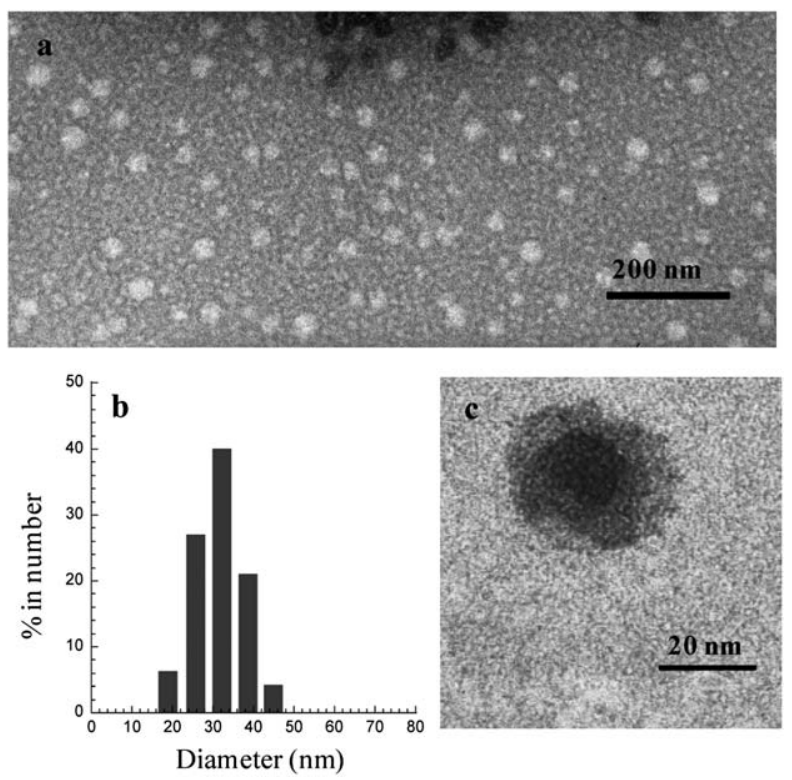

Fig. 6 (a) TEM micrograph of the aqueous mixture PEO113-b-PAA33/ oligochitosan observed with negative staining; (b) size distribution obtained from the histogram analysis of the TEM micrograph; (c) TEM micrograph of the aqueous mixture PEO113- $b$-PAA33/oligochitosan without negative staining.
At high $q$ values, the slope provides information on the conformation and local structure of the corona chains in solution: the power law behaviour of the intensity $I(q) \propto q^{-1.7}$ is characteristic of polymer chains well dispersed in a good solvent. ${ }^{4}$

In the Guinier domain $\left(q<0.04 \AA^{-1}\right)$, a good agreement was found with the Guinier law for spherical objects with a radius of gyration of $5 \mathrm{~nm}$. Hence, association between PEO113- $b$-PAA33 and oligochitosan led to the formation of micelles with a well defined core-corona structure, which is also supported by the low value of the $R_{\mathrm{g}} / R_{\mathrm{h}}$ ratio, equal to 0.3 characteristic of this type of nanostructure $\left(R_{\mathrm{h}}=15 \mathrm{~nm}\right)$.

Effect of salt concentration on the existence of the complex micelles. As the formation of complex micelles is based on electrostatic interactions between two oppositely charged polymers, it is expected that addition of salt influences micelle formation. A sufficient amount of added monovalent ions may lead to micelle dissociation by screening polyion charges. The light scattered intensity was plotted as a function of the sodium chloride $(\mathrm{NaCl})$ concentration for the PEO113- $b$-PAA33/oligochitosan mixture $(R=1)$ at $\mathrm{pH}=6$ (Fig. $\mathrm{S} 7 \dagger)$. The scattered intensity decreases with increasing ionic strength until a salt concentration of $0.4 \mathrm{~mol} \mathrm{~L}^{-1}$ is reached. The low value of the scattered light intensity reached at such ionic strength reveals that micelles have dissociated. Above $0.4 \mathrm{~mol} \mathrm{~L}^{-1}$, no further intensity variation is observed, highlighting that no micelle persists when more salt is added. This behavior is in accordance with previous results obtained by Kabanov et al., ${ }^{18}$ Cohen Stuart et al. ${ }^{14}$ and Gohy et al. ${ }^{19}$ who found a complete disaggregation of the micelles at salt concentrations above $0.5 \mathrm{~mol} \mathrm{~L}-1$.

The reversibility of the formation/dissociation process controlled by the ionic strength was also studied. After having increased the salt concentration up to $1 \mathrm{~mol} \mathrm{~L}^{-1}$ and triggered micelle dissociation, salt elimination was then performed by dialysis. When the salt concentration is increased up to $1 \mathrm{~mol} \mathrm{~L}^{-1}$, the initial monomodal population centered at $30 \mathrm{~nm}$ (Fig. S8a $\uparrow$ ) disappears. Instead, objects with diameters equal to 200 and $800 \mathrm{~nm}$ (Fig. S8b†) appear; the very low value of the corresponding scattered light intensity by these large objects indicates

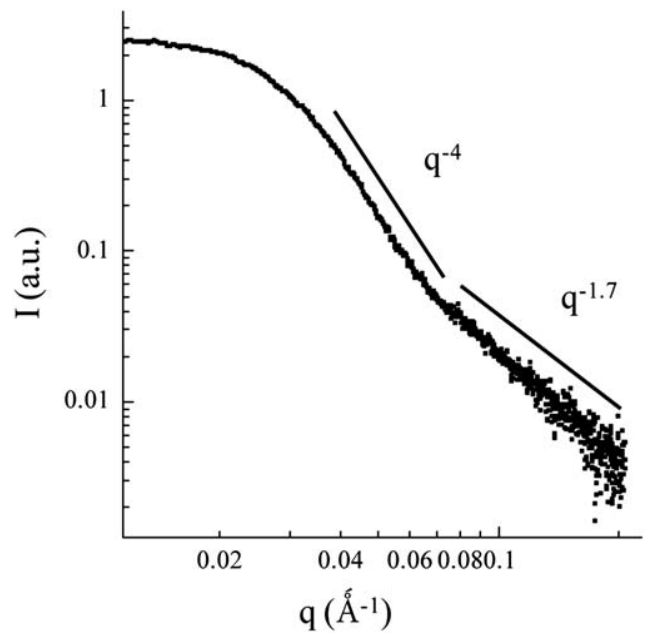

Fig. 7 Small angle X-ray scattering curve of the PEO113-b-PAA33/ oligochitosan system. 
that they are not numerous and composed of loose aggregates with a low density. At high ionic strength, interactions of PEO segments with sodium cations lead to partial PEO dehydration, which may lead to poorly defined aggregates of copolymers associated through PEO chains. ${ }^{42}$ After dialysis, a unimodal population forms back again (Fig. S8c†). Interestingly, the average size of the aggregates is higher than before salt addition. This size difference may arise from the fact that micelle formation occurs during dialysis and hence at a higher ionic strength than before salt addition. This may lead to larger and less dense cores (more hydrated), hence to larger objects.

Effect of the degree of polymerization of the PAA block on micelle formation. The influence of the PAA degree of polymerization on the micellization process was studied. Three copolymers with $\mathrm{DP}_{\mathrm{PAA}}=9,22$ and 33 but with the same $\mathrm{DP}_{\mathrm{PEO}}=113$ were mixed with oligochitosan. Fig. 8 shows the variations of the scattered intensities and hydrodynamic diameters as a function of $\mathrm{pH}$ for the three mixtures. Significative variations of $I$ and $D_{\mathrm{h}}$ are observed only in the cases of copolymers with $\mathrm{DP}_{\mathrm{PAA}}=22$
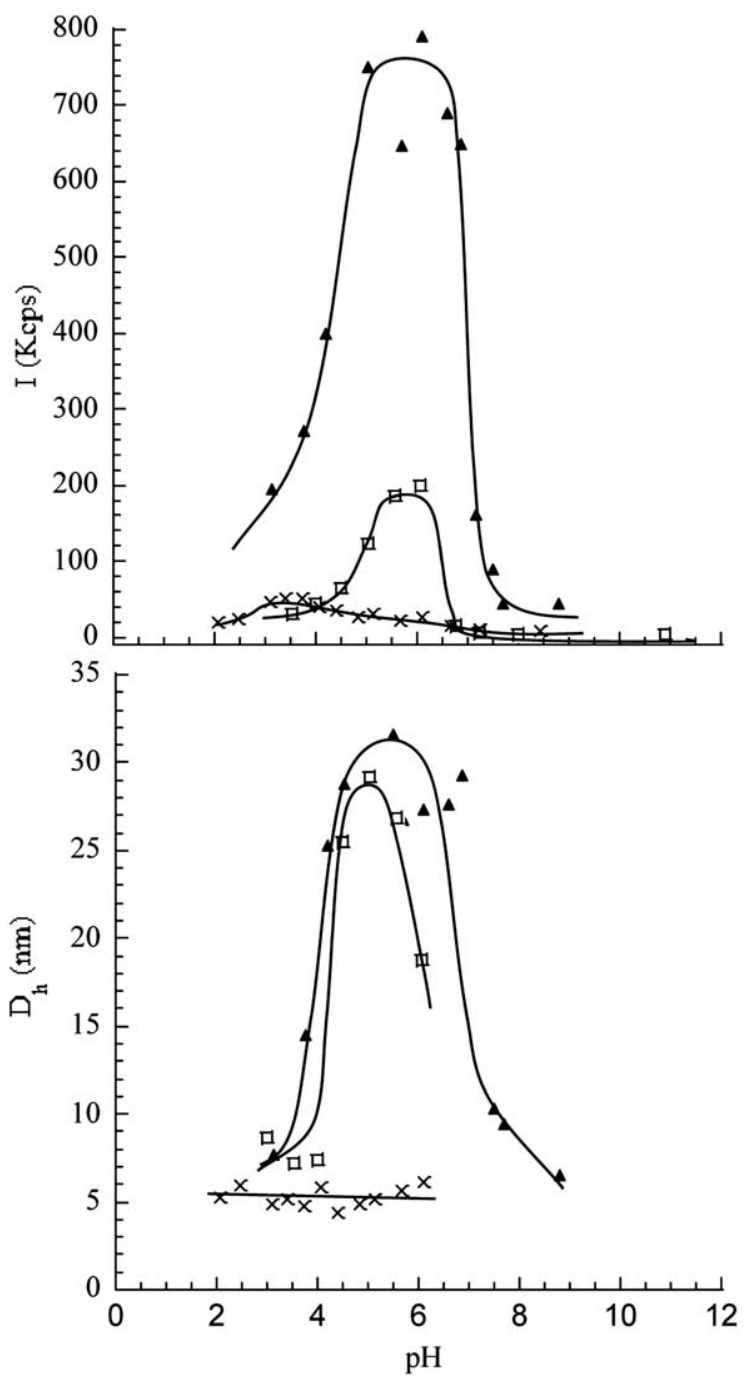

Fig. 8 Scattered intensity and hydrodynamic diameter plotted as a function of $\mathrm{pH}$ for mixtures composed of copolymers with $\mathrm{DP}_{\mathrm{PAA}}=9$ (crosses), 22 (empty squares) and 33 (triangles). and 33. The mixture between oligochitosan and the copolymer with the shortest PAA block (DP $=9$ ) does not lead to any variation whatever the $\mathrm{pH}$ value, suggesting that no micellization occurs. The $\mathrm{pH}$ domain of micelle formation with $\mathrm{DP}_{\mathrm{PAA}}=22$ $(4.5<\mathrm{pH}<6.5)$ is narrower than with $\mathrm{DP}_{\mathrm{PAA}}=33(4<\mathrm{pH}<$ 7.5), which suggests that stability of micelles as a function of $\mathrm{pH}$ is lower when the PAA block length is shorter. The optimal $\mathrm{pH}$ domain of micelle formation is nearly the same in both cases $(5<$ $\mathrm{pH}<6$ ). On this $\mathrm{pH}$ domain, the intensity measured with $\mathrm{DP}_{\mathrm{PAA}}=33$ is about four times higher than the intensity with $\mathrm{DP}_{\mathrm{PAA}}=22$. On the other hand, both hydrodynamic diameters and PDI are close: $D_{\mathrm{h}} \approx 30 \mathrm{~nm}$ and PDI $\approx 0.25$ (PDI data are shown in Fig. S9†).

According to the scaling relations determined by Cohen Stuart in the case of asymmetric block copolymers with a neutralhydrophobic diblock architecture (see ESI $\dagger$ ), the shorter the block length of the core, the lower the number of aggregation. The variation of the intensity in the case of the present PEO- $b$ PAA/oligochitosan system as a function of $\mathrm{DP}_{\mathrm{PAA}}$ in the optimal $\mathrm{pH}$ domain is perfectly in line with these scaling relations. As the scattered intensity measured in light scattering is related to the molecular weight of the scattering objects by the relation $I=$ $K C M$ ( $K$ is a constant depending on the instrument and on the refractive index of the medium, $C$ is the weight concentration in polymers and $M$ is the molecular weight of the scattering objects), it affords indirect information on the micelle aggregation number. The higher the measured intensity, the higher the $N_{\text {agg }}$ of the micelles. We can conclude that a DP $P_{\text {PAA }}$ of 33 leads to the formation of micelles with a higher $N_{\text {agg }}$ than a $D_{\text {PAA }}$ equal to 22 . The very close values of $D_{\mathrm{h}}$ with these two $\mathrm{DP}_{\mathrm{PAA}}$ values can be explained as follows. In the case of PEO113- $b$-PAA33, $R_{\mathrm{g}}=5 \mathrm{~nm}$ and $R_{\mathrm{h}}=15 \mathrm{~nm}$ were determined by SAXS and DLS respectively, this allows drawing a schematic picture of the micelle as shown in Fig. 9.

It is obvious on this picture that the use of the copolymer PEO113- $b$-PAA33, which is the copolymer with the longer PAA block studied in this work, leads to the formation of star-like micelles. The very low value of the gyration radius $\left(R_{\mathrm{g}}=5 \mathrm{~nm}\right)$ in comparison with the radius of the overall micelle evidences the star-like structure with a small core and a large corona. In that

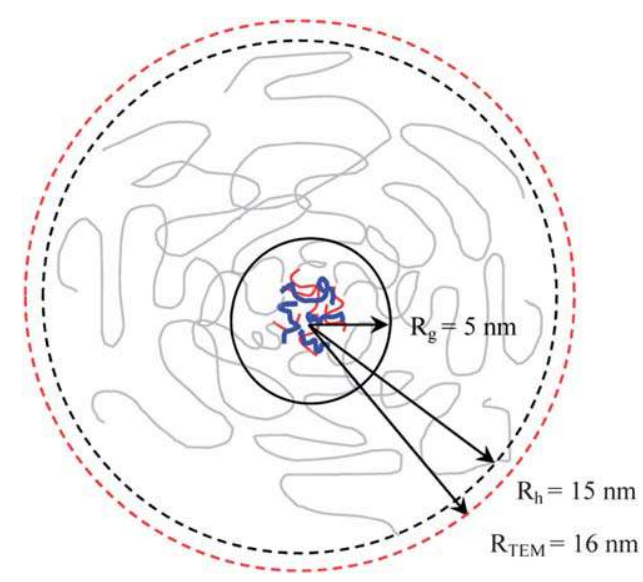

Fig. 9 Schematic picture of a complex micelle composed of the PEO113$b$-PAA33/oligochitosan system (PEO is in grey, PAA in red and the oligochitosan in blue). 
case, the effect of a variation of $\mathrm{DP}_{\text {core }}$ is very low on the overall dimensions of the micelles $\left(D_{\mathrm{h}}\right)$. The hydrodynamic diameter is essentially influenced by the value of the PEO length. A shorter PAA block forming the core leads to a decrease of the core radius, but, as the main contribution to the hydrodynamic diameter comes from the corona chains, this does not considerably change the $D_{\mathrm{h}}$ value.

When $\mathrm{DP}_{\mathrm{PAA}}=9$, no micelle formation is observed. This is certainly due to the fact that the ratio value of the length of the PAA block against the length of the PEO block is too low to ensure the formation of the micelles. The entropy gain related to the release of the PAA counter ions and the energy gain associated with the electrostatic complexation are insufficient to balance the configurational and conformational entropy loss of the polymers.

\section{Conclusions}

PEO- $b$-PAA/oligochitosan polyion complex micelles had been successfully used as new and original structure directing agents for the environment-friendly synthesis of well ordered mesoporous silica materials. Herein, the electrostatic complex micelles are studied in detail as a function of different parameters: the $\mathrm{pH}$, the ionic strength and the polymer block lengths. First, a series of PEO- $b$-PAA double hydrophilic block copolymers with PAA blocks of variable and well-controlled chain lengths was synthesized from PEO macroinitiators using atom transfer radical polymerization. ATRP of tBuA yielded well-defined PEO- $b$-PtBuA amphiphilic copolymers with a polydispersity $M_{\mathrm{w}} / M_{\mathrm{n}}$ lower than 1.03 . The quantitative and selective acidic hydrolysis of the PtBuA block allowed us to obtain the PEO- $b$ PAA DHBCs without breaking the ester linkage between the two blocks. The structure of the copolymer was further ascertained by capillary electrophoresis analyses.

In aqueous solution, the PAA block complexes the weak polybase, an oligochitosan, in well-chosen $\mathrm{pH}$ conditions, leading to the formation of polyion complex micelles with an oligochitosan/PAA-PEO core-corona structure. As the PAA block and oligochitosan are respectively a weak polyacid and a weak polybase, there exists two $\mathrm{pH}$ domains surrounding the $\mathrm{pH}$ domain of micelle formation on which the neutralization of one of the weak polyelectrolytes leads to the dissociation of the micelles: the micellization/dissociation process is then reversible as a function of the $\mathrm{pH}$. After micelle dissociation by adjusting the $\mathrm{pH}$ out of the central $\mathrm{pH}$ domain, re-formation of micelles is possible when $\mathrm{pH}$ is tuned back into the intermediate $\mathrm{pH}$ range. The possibility to control the micellization process in water is at the basement of the use of PIC micelles as reversible templates for the synthesis of mesoporous silica in an environmentally friendly way. Although the reversibility of the micellization process was indirectly evidenced through the satisfactory results obtained during the template removal in water from the silica material, it was necessary to investigate it in more detail. Furthermore, another parameter allowing to control micelle formation was put into evidence: the ionic strength. It was shown that adding a monovalent salt $(\mathrm{NaCl})$ into the micelle solution leads to micelle dissociation above $0.4 \mathrm{~mol} \mathrm{~L}^{-1}$ due to polyion charge screening. Removal of the salt by dialysis in water leads to the formation of micelles larger than the ones obtained without added salt.

Lastly, the study of the influence of the PAA block length on micelle formation and size showed that a critical PAA length exists below which complexation with oligochitosan does not lead to any micelle. When the PAA degree of polymerization is sufficiently high, well defined micelles are formed; their hydrodynamic diameter does not significantly vary with the PAA block size of DHBCs studied in this work $\left(\mathrm{DP}_{\mathrm{PAA}}=22\right.$ and 33$)$, but their aggregation number together with the extent of the $\mathrm{pH}$ range increase with the PAA block length.

\section{Acknowledgements}

The authors thank T. Cacciaguerra, G. Layrac, M.-F. Driole, P. Gonzales and C. Negrell-Guirao for technical support. CNRS is acknowledged for the visiting researcher grant allocated to $\mathrm{T}$. Nugay. We also thank the French Ministry of Research for financial support through the "ACI Jeune Chercheur" grant.

\section{References}

1 H. Cölfen, Macromol. Rapid Commun., 2001, 22, 219.

2 P. Kašparová, M. Antonietti and H. Cölfen, Colloids Surf., A, 2004, 250, 153.

3 C. Gérardin, N. Sanson, F. Bouyer, F. Fajula, J.-L. Putaux, M. Joanicot and T. Chopin, Angew. Chem., Int. Ed., 2003, 42, 3681.

4 N. Sanson, F. Bouyer, C. Gérardin and M. In, Phys. Chem. Chem. Phys., 2004, 6, 1463.

5 A. Aquil, S. Vasseur, E. Duguet, C. Passirani, J. P. Benoît, A. Roch, R. Müller, R. Jérôme and C. Jérôme, Eur. Polym. J., 2008, 44, 3191.

6 M. A. Cohen Stuart, W. T. S. Huck, J. Genzer, M. Müller, C. Ober, M. Stamm, G. B. Sukhorukov, I. Szleifer, V. V. Tsukruk, M. Urban, F. Winnik, S. Zauscher, I. Luzinov and S. Minko, Nat. Mater., 2010, 9, 101.

7 K. Kataoka, A. Harada and Y. Nagasaki, Adv. Drug Delivery Rev., 2001, 47, 113.

8 A. Boudier, A. Aubert-Pouessel, P. Louis-Plence, C. Gerardin, C. Jorgensen, J.-M. Devoisselle and S. Begu, Biomaterials, 2009, 30, 233.

9 G. Bokias, G. Staikos and I. Iliopoulos, Polymer, 2000, 41, 7399.

10 E. Tsuchida and K. Abe, Adv. Polym. Sci., 1982, 45, 2.

11 H. Dautzenberg and N. Karibyants, Macromol. Chem. Phys., 1998, 200, 118.

12 A. Zintchenko, H. Dautzenberg, K. Tauer and V. Khrenov, Langmuir, 2002, 18, 1386.

13 B. Vroman, I. Ferreira, C. Jérôme, R. Jérôme and V. Préat, Int. J. Pharm., 2007, 344, 88.

14 M. A. Cohen Stuart, N. A. M. Besseling and R. G. Fokking, Langmuir, 1998, 14, 6846.

15 S. Van der Burgh, A. de Keizer and M. A. Cohen Stuart, Langmuir, 2004, 20, 1073.

16 A. Harada and K. Kataoka, Macromolecules, 1998, 31, 288.

17 A. Harada and K. Kataoka, Science, 1999, 65, 283.

18 A. V. Kabanov, T. K. Bronich, V. A. Kabanov, K. Yu and A. Eisenberg, Macromolecules, 1996, 29, 6797.

19 J.-F. Gohy, S. K. Varshney and R. Jérôme, Macromolecules, 2001, 34, 3361.

20 S. Holappa, T. Andersson, L. Kantonen, P. Plattner and H. Tenhu, Polymer, 2003, 44, 7907.

21 G. Yohannes, S. Holappa, S. K. Wiedmer, T. Andersson, H. Tenhu and M.-L. Riekkola, Anal. Chim. Acta, 2005, 542, 222.

22 N. Baccile, J. Reboul, B. Blanc, B. Coq, P. Lacroix-Desmazes, M. In and C. Gérardin, Angew. Chem., Int. Ed., 2008, 47, 8433.

23 C. Y. Kresge, M. E. Leonowicz, W. J. Roth, J. C. Vartuli and J. S. Beck, Nature, 1992, 359, 710.

24 G. S. Attard, J. C. Glyde and C. G. Goltner, Nature, 1995, 378, 366. 
25 A. Firouzi, D. Kumar, L. M. Bull, T. Besier, P. Sieger, Q. Huo, S. A. Walker, J. A. Zasadzinski, C. Glinka, J. Nicol, D. Margolese, G. D. Stucky and B. F. Chmelka, Science, 1995, 267, 1138.

26 C. Sanchez, G. J. de A. A. Soler-Illia, F. Ribot, T. Lalot, C. R. Mayer and V. Cabuil, Chem. Mater., 2001, 13, 3061.

27 D. Y. Zhao, J. L. Feng, Q. S. Huo, N. Melosh, G. H. Fredrickson, B. F. Chmelka and G. D. Stucky, Science, 1998, 279, 548.

$28 \mathrm{C}$. Yu, Y. Yu and D. Zhao, Chem. Commun., 2000, 575.

29 N. Anik, M. Airiau, M.-P. Labeau, C.-T. Vuong, J. Reboul, P. Lacroix-Desmazes, C. Gérardin and H. Cottet, Macromolecules, 2009, 42, 2767.

30 J. M. Kim, Y. Sakamoto, Y. K. Hwang, Y. U. Kwon, O. Terasaki, S. E. Park and G. D. Stucky, J. Phys. Chem. B, 2002, 106, 2552.

31 R. N. Keller and H. D. Wycoff, Inorg. Synth., 1946, $2,1$.

32 K. Matyjaszewski, S. Gaynor, H.-J. Paik, K. Pintauer, J. Pyun, M. Teodorescu, J. Xia and X. Zhang, Pat., WO0056795, Carnegie Mellon University, 2000.
33 M. Ranger, M.-C. Jones, M.-A. Yessine and J.-C. Leroux, J. Polym. Sci., Part A: Polym. Chem., 2001, 39, 3861.

34 A. D. Kelly and K. Matyjaszewsky, Macromolecules, 2000, 33, 4039.

35 S. Hou, E. L. Charkof, D. Taton and Y. Gnanou, Macromolecules, 2003, 36, 3874.

36 B. Guillemet, PhD, Université de Bordeaux, 2005.

37 L. Dzhekieva, M. Rocaboy, F. Kerff, P. Charlier, E. Sauvage and R. F. Pratt, Biochemistry, 2010, 49, 6411.

38 J. Qin, X. Jiang, L. Gao, Y. Chen and F. Xi, Macromolecules, 2010, 43, 8094 .

39 G. S. Manning, J. Chem. Phys., 1969, 51, 924.

40 I. K. Voets, A. de Keizer and M. A. Cohen Stuart, Macromolecules, 2007, 40, 2158.

41 N. Sanson, J.-L. Putaux, M. Destarac, C. Gérardin and F. Fajula, Macromol. Symp., 2005, 226, 279.

42 F. E. Bailey and R. W. Callard, J. Appl. Polym. Sci., 1959, 1, 56. 